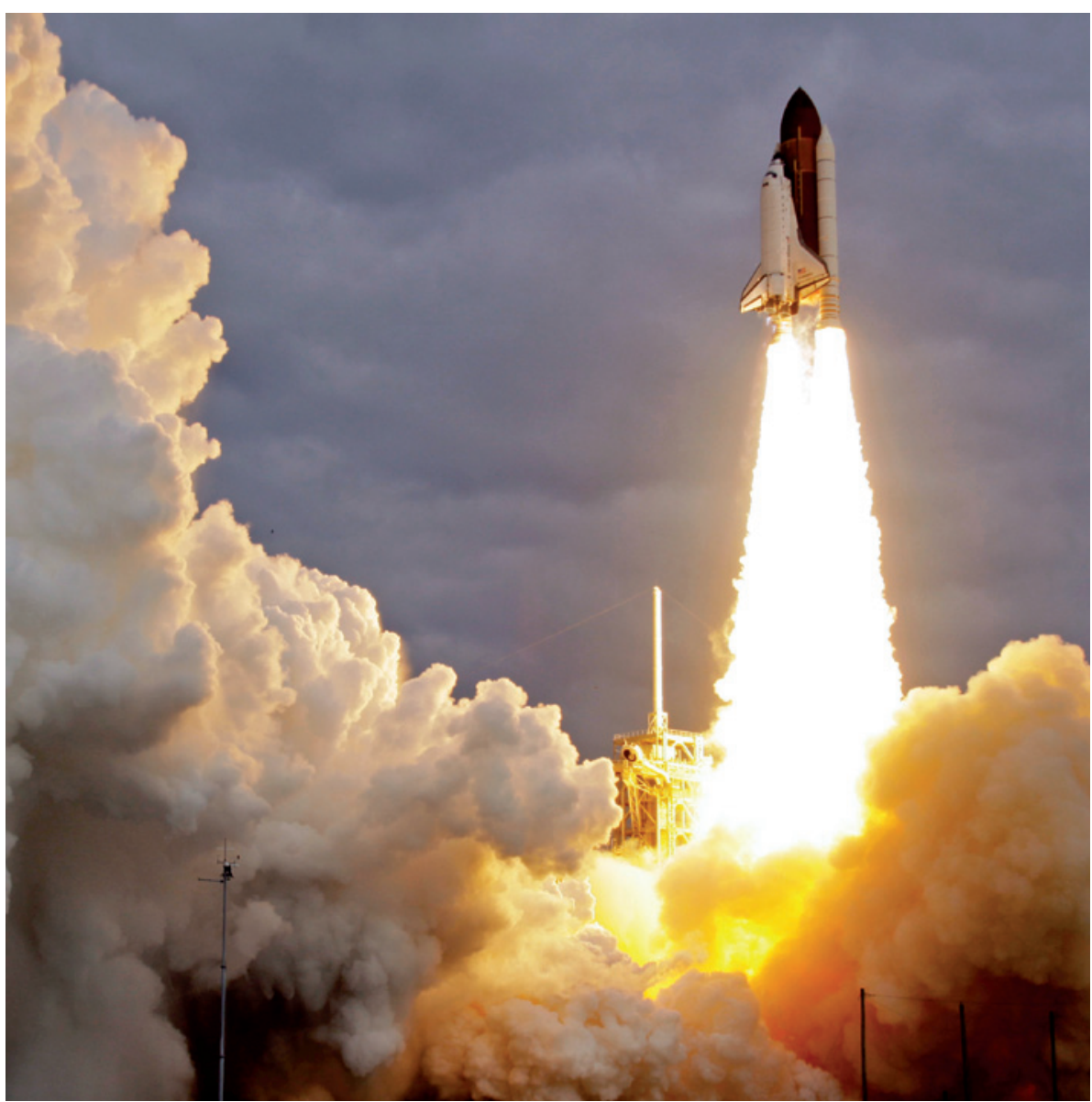

The space shuttle Endeavour launched for the last time on 16 May. Only one shuttle flight remains.

\title{
SPACE EXPLORATION
}

\section{Shuttle's end spells change at NASA}

\section{As the shuttle flies its penultimate mission, the US space agency seeks to fill a looming gap in crew transport.}

\section{BY ALEXANDRA WITZE}

$\mathrm{N}$ ear the Kennedy Space Center in Florida, where the space shuttles thunder into orbit, roadside signs reveal the deep ties that the local community feels to the US space programme. The ties are both spiritual and economic: church signs wish the shuttle Godspeed before each launch, and liquor stores tout their selection as 'out of this world'.

That relationship is now heading for an extended and painful hiatus. On 16 May, after several weeks of delays, the space shuttle Endeavour embarked on the penultimate shuttle flight, carrying a large cosmic-ray

detector (see Nature 473, 13-14; 2011) to the International Space Station (ISS). The final, 135th launch of the 30-year shuttle programme will take place by late summer, when Atlantis is set to take flight to ferry another load of astronauts, equipment and supplies to the station.

"Although we're ending the space-shuttle programme, we are not ending the nation's human space-flight programme," says Philip

\section{$\rightarrow$ NATURE.COM}

Seven experts ponder the future of NASA:

go.nature.com/izs9zr McAlister, acting director of NASA's commercial space-flight development programme. "It's evolving into an exciting new paradigm." Before that new phase begins, however, NASA will face years with no crewed spaceship of its own, and the Space Coast, the region around the Kennedy centre, will lose some 8,000 space-related jobs.

In the short term, NASA will have to buy seats aboard Russia's Soyuz capsules, now the only way to deliver crew members to the ISS. The next such flight, slated for 7 June, will carry one astronaut each from Russia, Japan and the United States to the station. The United States also has places reserved on the ten further Soyuz flights that are scheduled before the end of 2013 .

In the long term, NASA expects to give private companies the responsibility of getting astronauts into low-Earth orbit, an approach championed by US President Barack Obama. On 18 April, the agency announced that it would share US\$269 million among four companies developing commercial space-flight options: SpaceX, of Hawthorne, California; Boeing, of Houston, Texas; Blue Origin of Kent, Washington; and Sierra Nevada of Louisville, Colorado. All say that they will begin flying crewed spacecraft in 2014-15.

SpaceX has already flown its unmanned Dragon capsule into orbit and recovered it successfully, the only private company to manage such a feat. NASA is expected to decide in the coming weeks whether to combine the second and third Dragon flights, scheduled for later this year, to advance directly to a mission that docks with the ISS - an option strongly endorsed by Elon Musk, chief executive of SpaceX.

For NASA, which has always relied on its own or Russian rockets to get astronauts into space, the commercial crew-transportation business represents a fundamental shift to a different - and untested - way of doing things. Many within the agency are upbeat, despite the unknowns.

"The shuttle was one of the ways to go to space," says Chris Hadfield, an astronaut with NASA and the Canadian Space Agency, who will spend six months on the ISS next year, three as commander. "It was not the only way."

Commercial suppliers will also be needed to ferry cargo - including research experiments - to the ISS. The Soyuz flights can carry very little payload, says Tara Ruttley, the station's associate programme scientist. NASA has contracted for 12 cargo flights with SpaceX and 8 with Orbital Sciences of Dulles, Virginia, to begin as early as next year. Russia's unmanned Progress resupply ships can also carry research payloads up to the station.

Freed of the need to develop transport for low-Earth orbit, the thinking goes, NASA can focus on the task handed to it by Congress in last October's NASA Authorization Act. By 2016, the agency is supposed to develop a heavy-lift rocket and a crew vehicle to send astronauts to distant targets such as the Moon or near-Earth asteroids. The rocket will draw 
on work done under the now-defunct Constellation programme, developed during the previous administration as a next-generation replacement for the shuttle.

The new programme reflects the concerns of congressional lawmakers who fear the decline of NASA and of regions dependent on the jobs it has provided, such as the Space Coast (see Nature 472, 16; 2011). In an opinion piece published in the Orlando Sentinel on 26 April, US Senator Marco Rubio (Republican, Florida), chastised Obama for not allocating enough money for the heavy-lift vehicle to meet its target launch date in 2016. "The bottom-line impact of the president's space agenda is a full retreat from America's long-standing commitment to space exploration," Rubio wrote. Others echo Rubio's ire - something that could come back to haunt Obama, given Florida's probable role as a key battleground state in the 2012 presidential election.

For shuttle workers facing imminent job loss, commercial flights seem a distant dream Engineers have been dismantling shuttlerelated equipment at Kennedy's spare launch pad and preparing the already-retired Discovery shuttle for shipment to its final home at a Smithsonian Institution museum near Washington DC. For now, the era that is passing commands far more attention than the one that is promised, as a technical community that is used to making space a way of life settles in for a long stint on the ground.

\section{Japan rethinks its energy policy}

Renewables come to the fore as universities take the lead on electricity conservation.

\section{BY DAVID CYRANOSKI}

$\mathrm{I}$ $\mathrm{n}$ the aftermath of the Fukushima disaster, power shortages have forced one of the world's most energy-efficient countries to make do with even less. That may become the norm after Prime Minister Naoto Kan last week shelved a 2010 goal to build 14 nuclear reactors over the next 20 years.

With Japan's energy policy in tatters, advocates of renewable energy and efficiency savings are seizing the opportunity to argue their case. But the measures will have to make up a major shortfall: under the previous plan, the country's nuclear generating capacity was set to double, to meet half of the nation's electricity needs (see Nature 472, 143-144; 2011).

Kan had little choice but to change course after the accident at the Fukushima Daiichi nuclear plant, which was triggered by an enormous earthquake and tsunami on 11 March. Demonstrators have been calling for the closure of some or all of Japan's 54 nuclear reactors ever since. In addition to ditching plans for new plants, Kan has promised a much greater emphasis on efficiency measures and renewable sources, which Japan has been relatively slow to adopt. "Before $11 \mathrm{March}$, there was a black cloud over energy policy, formed by industry and the industry ministry. Now there's a crack in that," says Tetsunari Iida, executive director of the Institute for Sustainable Energy Policies in Tokyo, which advises the government on renewable energy.

Last month, the institute set out an ambitious vision for the country's energy mix. Its plan for the Tohoku region calls for energy demand to be reduced such that all the region's needs can be met by renewable sources by

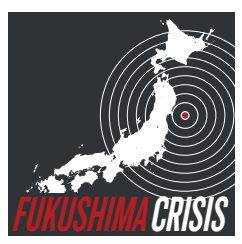

$\rightarrow$ WWW.NATURE. COM/JAPANQUAKE
2020. Because Tohoku saw the greatest damage from the earthquake, and has a lot of potential to exploit wind power, the institute thinks that renewables could be introduced quickly while creating jobs to regenerate the local economy.

Countrywide, the institute says that renewables' share of the energy mix should rise from about $8 \%$ to $30 \%$ by 2020 , and to $100 \%$ by 2050 , a strategy that requires demand to be halved. "It

\section{POWER CUT}

The University of Tokyo is using at least 30\% less electricity than it was just before the devastating 11 March earthquake.

$$
60
$$

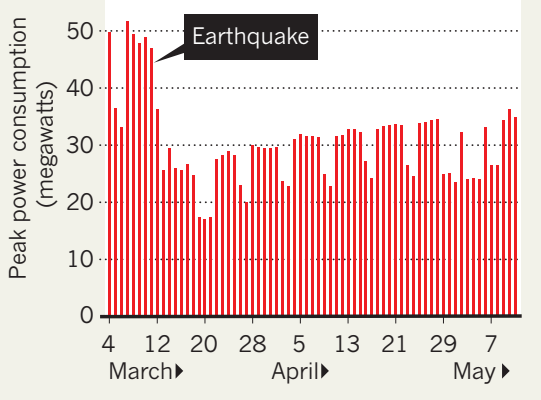

is technically feasible but politically challenging," says Iida. Iida helped to draft a bill that guarantees utilities a high price for electricity from renewables. The bill was, coincidentally, finalized by the government on 11 March and is expected to become law next month.

Tatsuo Oyama, an engineer at the National Graduate Institute for Policy Studies in Tokyo who models electricity investment scenarios, says that the target might be possible in Tohoku. But he warns that the country should not become dependent on unpredictable energy sources, and that the waning support for nuclear energy could be reversed if Japan tackles the aftermath of the Fukushima disaster effectively.
Tokyo's universities are already proving that the country still has room for energy savings. The University of Tokyo, for example, has cut peak power usage by $30-40 \%$ by turning off lights and air-conditioning, shutting down extra lifts and running energy-intensive experiments at night (see 'Power cut').

Researchers at the university say that their low-energy lives are inconvenient, but largely manageable. Restricting the use of some equipment to off-peak hours is "realistic and feasible", says neurochemist Haruhiko Bito, although he adds that scheduling researchers' energy use can be time-consuming and depressing. And chemist Eiichi Nakamura says that the loss of instruments and computer systems has slowed research. "The electricity shortage made us realize that we can indeed save energy easily by $10 \%$, but that $30 \%$ cuts will impact productivity in the longer term, he says. Others worry that the strategy will discourage younger scientists by forcing them to work at night.

The challenge will only intensify in the sweltering summer months. Animal facilities and sensitive instruments will take priority for precious cooled air, while professors and students sweat in rooms with minimal air-conditioning. Staggered work schedules and holidays are being considered to mitigate the effects.

With Japan's energy strategy in flux, these conservation policies will probably be in place for the foreseeable future. "This is tough but, in another sense, this has a positive aspect," says Toshio Yamagata, an ocean modeller at the University of Tokyo who has had to cope with a $30 \%$ cut in supercomputer operating time. "It is a good occasion for us to realize our resources are not infinite." He adds that a greater appreciation of energy could lead to more elegant experiments. "We will design experiments more carefully and digest the results in a deeper way, rather than just obtaining tonnes of data." 